\title{
PERBEDAAN EFEKTIVITAS EKSTRAK JAHE DENGAN EKSTRAK KUNYIT DALAM MENGURANGI NYERI DISMENORHEA PRIMER PADA MAHASISWI DI ASRAMA JURUSAN KEBIDANAN POLTEKKES SURAKARTA
}

\author{
Gita Kostania, Anik Kurniawati \\ Kementerian Kesehatan Politeknik Kesehatan Surakarta Jurusan Kebidanan
}

\begin{abstract}
Dysmenorrhoea, Ginger, Turmeric. The aim of this study was to determine differences of the effectiveness of ginger extract with turmeric extract on reducing pain in primary dysmenorrhoea on dormitory student at Midwifery Department of Health Polytechnic of Surakarta. The design of this research is experimental design, with true experimental approach, using a pretest-posttes control group design. Criteria sampling is purposive random sampling, a total sample of 60 respondents $(55 \%$ of the population, nomogram Harry King Samples), divided into three equal groups: ginger extract treatment group, turmeric extract treatment group, and placebo group. Each group consist of 20 respondents. Results: the data was in normal distribution, the total number of respondents at the end of the study was 56 respondents (ginger extract treatment $=19$, turmeric extract treatment $=19$, and placebo=18). There are differences in the effectiveness of ginger extract with turmeric extract in reducing pain in primary dysmenorrhoea on dormitory student at Midwifery Department of Health Polytechnic of Surakarta ( $p$-value $=0.04<0.05$ ). Extracts of ginger is more effective in reducing menstrual pain than turmeric extract $(t$-test $=9.690>4.802)$.
\end{abstract}

Keywords: Dysmenorrhoea, Ginger, Turmeric.

Abstrak: Dismenorea, Jahe, Kunyit. Tujuan penelitian ini adalah untuk mengetahui perbedaan efektivitas ekstrak jahe dengan ekstrak kunyit dalam mengurangi nyeri dismenorea primer pada mahasiswi di asrama Kebidanan Poltekkes Surakarta. Jenis penelitian adalah eksperiment, dengan pendekatan true experimental, menggunakan rancangan pretest-posttes control group design. Kriteria sampel adalah purposive random sampling, jumlah total sampel sebanyak 60 responden (55\% dari populasi, Nomogram Harry King Sampel), dibagi menjadi tiga kelompok sama besar: kelompok perlakuan ekstrak jahe, kelompok perlakuan ekstrak kunyit, dan kelompok placebo. Masing-masing kelompok berjumlah 20 responden. Hasil: data berdistribusi normal, dengan jumlah total responden pada akhir penelitian 56 (perlakuan ekstrak jahe $=19$, ekstrak kunyit=19, dan placebo=18). Terdapat perbedaan efektivitas ekstrak jahe dengan ekstrak kunyit dalam mengurangi nyeri dismenorea primer pada mahasiswi di asrama Kebidanan Politeknik Kesehatan Surakarta $(\mathrm{p}=0,04<0,05)$. Ekstrak jahe lebih efektif dalam mengurangi nyeri haid dibanding ekstrak kunyit (t-hitung=9,690>4,802).

Kata Kunci: Dismenorea, Jahe, Kunyit. 


\section{PENDAHULUAN}

Dismenorhea merupakan nyeri perut bagian bawah yang terjadi saat menstruasi, terkadang rasa nyeri tersebut meluas hingga ke pinggang, punggung bagian bawah dan paha. Nyeri ini dapat memaksa penderita untuk istirahat dan meninggalkan pekerjaan atau cara hidupnya sehari-hari, untuk beberapa jam atau beberapa hari. Penyebab terjadinya dismenorhea adalah adanya jumlah prostaglandin $\mathrm{F}_{2 \alpha}$ yang berlebihan pada darah mentruasi, sehingga merangsang hiperaktivitas uterus dan terjadinya kejang otot uterus (Wilson, 2006). Berdasarkan penyebabnya dibedakan menjadi dua, yaitu dismenorhea primer dan sekunder. Dismenorhea primer biasanya terjadi mulai dari pertama haid/menarche usia 10-15 tahun sampai usia 25 tahun yang disebabkan oleh kontraksi uterus, dan tidak terdapat hubungan dengan kelainan ginekologi. Sedangkan dismenorhea sekunder disebabkan oleh kelainan yang terdapat dalam uterus dan saluran reproduksi.

Kejadian dismenorhea primer di seluruh dunia rata-rata lebih dari 50\%, yaitu terjadi pada wanita usia produktif. Prevalensi di Amerika Serikat diperkirakan 45-90\%, dan di Swedia sekitar 72\%. Sementara di Indonesia angkanya diperkirakan 55\% (Lie, 2004). Puncak insiden dismenorhea primer terjadi pada akhir masa remaja dan di awal usia 20-an tahun. Hasil penelitian yang lain menjelaskan bahwa $80 \%$ remaja usia 19-21 tahun mengalami dismenorhea, sebanyak $15 \%$ membatasi aktifitas harian mereka ketika menstruasi dan membutuhkan obat-obatan untuk mengurangi rasa nyerinya, dan sebanyak 8-10\% tidak mengikuti pembelajaran di kelas dengan baik (Desfietni, 2012).
Upaya-upaya untuk mengatasi dan menyembuhkan dismenorhea primer diantaranya adalah dengan mengkonsumsi obat-obatan, istirahat yang cukup, olahraga teratur, pemijatan dan kompres hangat. Selain itu, nyeri menstruasi juga dapat diobati dengan tanaman obat atau ramuan herbal. Terapi ramuan herbal dapat dilakukan dengan cara mengkonsumsi obat tradisional yang berasal dari bahan-bahan tanaman tradisional. Beberapa bahan tanaman tradisional yang terpercaya dapat mengurangi rasa nyeri saat menstruasi diantaranya adalah tapak liman, temu putih, jahe, kunyit, dan sidaguri (Leli, 2011).

Bahan yang umum digunakan untuk mengurangi nyeri menstruasi adalah kunyit dan jahe. Kunyit biasa digunakan sebagai pereda nyeri dan pelancar menstruasi. Sedangkan penggunaan jahe untuk mengurangi nyeri dismenorea masih jarang, padahal jahe juga dapat digunakan untuk meredakan nyeri, dimana bagian rimpangnya berfungsi sebagai analgesik, antipiretik dan antiinflamasi (Rahnama, 2012).

Penelitian ini bertujuan untuk mengetahui perbedaan efektivitas ekstrak jahe dengan ekstrak kunyit dalam mengurangi nyeri dismenorea primer pada mahasiswi di asrama Kebidanan Politeknik Kesehatan Surakarta.

\section{METODE PENELITIAN}

Jenis penelitian ini adalah eksperiment, menggunakan rancangan pretest-posttest control group design. Penelitian dilakukan di asrama jurusan kebidanan Poltekkes Kemenkes Surakart, pada bulan Januari sampai dengan Juli 2015 . 
Populasi target dalam penelitian ini adalah seluruh mahasiswi di asrama jurusan kebidanan Poltekkes Surkarta, sedangkan populasi aktual adalah mahasiswi yang mengalami dismenorea di asrama jurusan kebidanan Poltekkes Surkarta. Jumlah populasi target sebanyak 240 mahasiswi, dan populasi actual sebesar 45\%, yaitu 108 mahasiswi.Teknik pengambilan sampel dalam penelitian ini adalah purposive random sampling. Kriteria purposive: mahasiswi yang mengalami dismenorea setiap menstruasi atau pre menstruasi minimal tiga kali siklus menstruasi terakhir, siklus haid antara 21 sampai dengan 35 hari, durasi menstruasi tiga sampai tujuh hari, dan mahasiswi tidak mengkonsumsi obat analgetik selama penelitian berlangsung. Variabel bebas (faktor) dalam penelitian ini adalah pemberian ekstrak jahe dan pemberian ekstrak kunyit. Sedangkan variabel terikat (efek) dalam penelitian ini adalah nyeri dismenorea primer. Pemberian ekstrak jahe yaitu memberikan ekstrak jahe dalam bentuk sediaan kapsul pada responden penelitian dengan dosis tunggal 500mg, dikonsumsi sebanyak tiga kali dalam sehari setiap 8 jam. Pemberian ekstrak kunyit yaitu memberikan ekstrak kunyit dalam bentuk sediaan kapsul pada responden penelitian dengan dosis tunggal 500mg, dikonsumsi sebanyak tiga kali dalam sehari setiap 8 jam. Sedangkn nyeri dismenorea primer adalah nyeri pada perut bagian bawah yang timbul sebelum dan saat menstruasi, oleh karena kram pada rahim, dapat timbul mulai dari perut bagian bawah, pinggang, punggung bawah dan paha.

Instrument yang digunakan berupa lembar observasi yang terdiri atas identitas dan karakteristik responden, serta hasil observasi yang dilakukan sendiri oleh responden sesuai dengan yang dirasakannya sebelum dan setelah perlakuan. Keadaan nyeri dismenorea primer diukur menggunakan NRS (Numeric Rating Scale) yang dikombinasikan dengan FPS (Faces Pain Score). Dalam hal ini, responden menilai nyeri dengan menggunakan skala 0-10. Responden diminta memberikan penilaian rasa nyeri yang mereka rasakan mulai dari 0 (tidak terasa nyeri) hingga 10 (nyeri terparah yang sangat hebat). Masingmasing tingkatan nyeri dilengkapi gambar mulai tersenyum (tidak terasa nyeri) dan berlinang air mata (nyeri terparah). Responden melingkari angka sesuai dengan NRS, dengan bantuan gambar FPS.

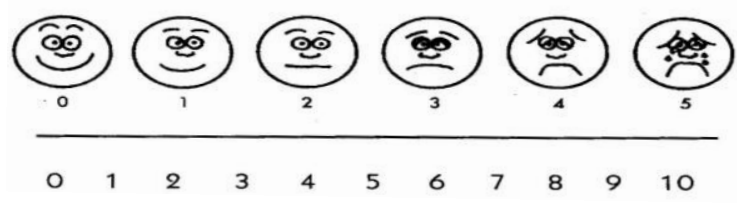

Gambar 1. Kombinasi Skala Nyeri Haid NRS (Numeric Rating Scale)

Setelah didapatkan sampel penelitian berdasarkan kelompoknya, maka peneliti memberikan pengarahan pada responden penelitian terkait perlakuan yang akan diberikan, dan dilanjutkan dengan pemberian inform consent. Responden mengkonsumsi ekstrak dalam sediaan kapsul sebanyak tiga kali sehari pada hari pertama menstruasi. Kapsul dosis pertama segera diminum saat serangan timbul, dan setiap 8 jam sampai dosis ketiga. Pengambilan data atau hasil observasi dilakukan empat kali, yaitu sebelum mengkonsumsi kapsul, dan masing-masing 2 jam setelah mengkonsumsi ekstrak. Peneliti melakukan pengawasan dan evaluasi pada responden selama penelitian berlangsung. 


\section{HASIL PENELITIAN}

Jumlah total responden pada akhir penelitian berjumlah 56 orang, pada kelompok ekstrak jahe $=19$ orang, ekstrak kunyit=19 orang, dan control placebo=18 orang. Pengolahan data menggunakan sistem komputerisasi SPSS-17. Uji prasyarat masing-masing kelompok menggunakan Shapiro Wilk. Pada kelompok ekstrak jahe $\mathrm{P}=0,406$ dan kelompok ekstrak kunyit=0,577. Nilai tersebut $\mathrm{P}>0,05$, sehingga disimpulkan bahwa data berdistribusi normal.

\section{Karakteristik Responden}

Karakteristik responden penelitian meliputi: umur responden, umur menarche, dan indeks masa tubuh.

\section{Tabel 1}

Karakteristik Responden: Umur Responden, Umur Menarche dan Indeks Masa Tubuh (IMT) Kelompok 1, 2 dan 3 Saat Penelitian Berlangsung

\begin{tabular}{|c|c|c|c|}
\hline \multirow[t]{2}{*}{ Karakteristik } & \multicolumn{3}{|c|}{ Mean } \\
\hline & $\begin{array}{c}\text { Kelompok } \\
1 \\
\text { (Ekstrak } \\
\text { Jahe) } \\
\end{array}$ & $\begin{array}{c}\text { Kelompok } \\
2 \\
\text { (Ekstrak } \\
\text { Kunyit) } \\
\end{array}$ & $\begin{array}{c}\text { Kelompok } \\
3 \\
\text { (Kontrol) }\end{array}$ \\
\hline $\begin{array}{l}\text { Umur } \\
\text { Responden }\end{array}$ & 19 & 19 & 19.1 \\
\hline $\begin{array}{l}\text { Umur } \\
\text { Menarche }\end{array}$ & 12.6 & 12.6 & 12.2 \\
\hline $\begin{array}{l}\text { Indeks Masa } \\
\text { Tubuh }\end{array}$ & 20.3 & 19.9 & 20.5 \\
\hline
\end{tabular}

Berdasarkan tabel di atas, dapat disimpulkan bahwa umur responden pada saat penelitian dilakukan pada masingmasing kelompok menunjukkan mean yang sama, yaitu usia 19 tahun. Karakteristik umur menarche responden juga menunjukkan mean yang hampir sama, yaitu pada usia antara 12-13 tahun. Begitu pula untuk karakteristik Indeks Masa Tubuh (IMT) menunjukkan mean yang hampir sama, selisih tidak mencapai angka 1 poin.

\section{Efektivitas Ekstrak Jahe dalam Mengurangi Nyeri Dismenorea Primer}

Untuk mengetahui efektivitas ekstrak jahe dalam mengurangi nyeri dismenorhea primer, maka dilakukan perhitungan menggunakan t-test sampel berpasangan pada kelompok perlakuan yang kemudian dibandingkan dengan kelompok kontrol.

Tabel 2

Uji Statistik Efektivitas Ekstrak Jahe dalam Mengurangi Nyeri Dismenorhea Primer

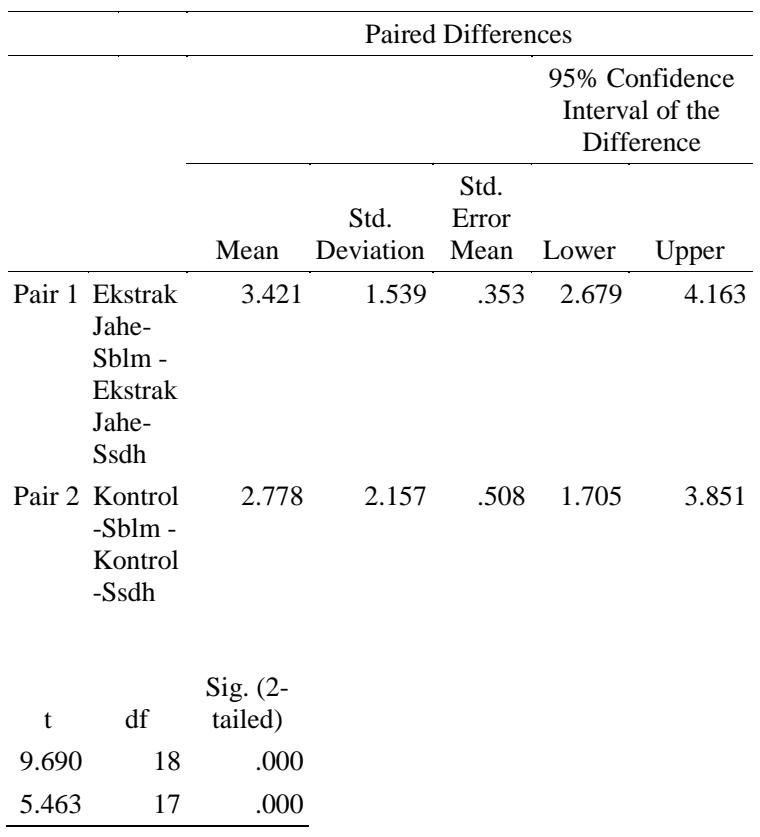

Nilai t-hitung pada kelompok perlakuan (ekstrak jahe) dengan $\mathrm{df}=18$ sebesar 9,690 > t-tabel=2,101, dengan nilai $\mathrm{p}=0,001$. Maka dapat dikatakan ada beda tingkatan nyeri dismenorea primer antara sebelum dan sesudah mengkonsumsi ekstrak jahe. Sedangkan nilai t-hitung pada kelompok kontrol (placebo) dengan $\mathrm{df}=17$ sebesar 5,463 $>\mathrm{t}$ - 
tabel $=2,110$, dengan nilai $\mathrm{p}=0,001$. Hal ini juga dapat dikatakan ada beda tingkatan nyeri dismenorea primer antara sebelum dan sesudah mengkonsumsi placebo.

Apabila dilihat dari nilai mean dan t-hitung pada kedua kelompok, keduanya menunjukkan bahwa nilai mean dan thitung kelompok perlakuan (ekstrak jahe) $>$ kelompok control (placebo), yaitu mean $3,421>2,778$ dan t-hitung 9,690>5,463, maka dapat disimpulkan bahwa pemberian ekstrak jahe efektif dalam mengurangi nyeri dismenorea primer.

\section{Efektivitas Ekstrak Kunyit dalam Mengurangi Nyeri Dismenorea Primer}

Untuk mengetahui efektivitas ekstrak kunyit dalam mengurangi nyeri dismenorhea primer, maka dilakukan perhitungan menggunakan t-test sampel berpasangan pada kelompok perlakuan yang kemudian dibandingkan dengan kelompok kontrol.

Tabel 3

\section{Uji Statistik Efektivitas Ekstrak Kunyit dalam Mengurangi Nyeri Dismenorhea Primer}

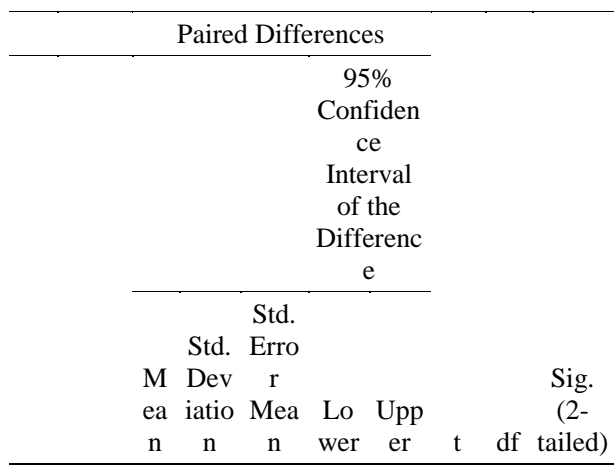

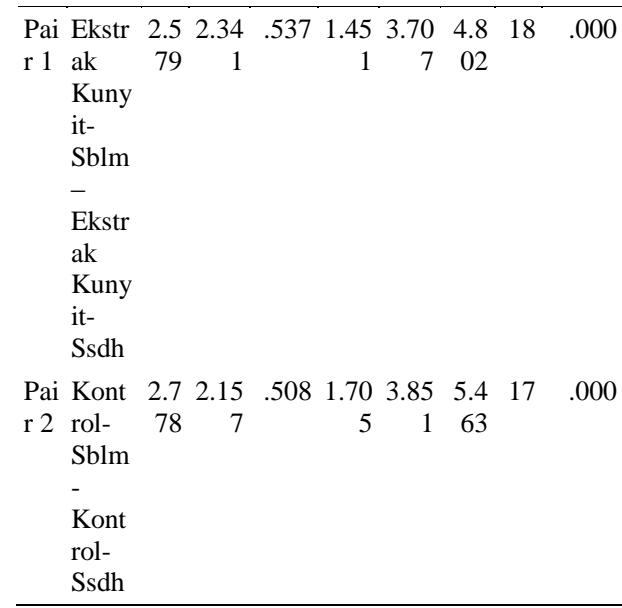

Nilai t-hitung pada kelompok perlakuan (ekstrak kunyit) dengan $\mathrm{df}=18$ sebesar 4,802 > t-tabel=2,101, dengan nilai $\mathrm{p}=0,001$. Maka dapat dikatakan ada beda tingkatan nyeri dismenorea primer antara sebelum dan sesudah mengkonsumsi ekstrak kunyit. Sedangkan nilai t-hitung pada kelompok kontrol (placebo) dengan $\mathrm{df}=17$ sebesar 5,463 > ttabel $=2,110$, dengan nilai $p=0,001$. Hal ini juga dapat dikatakan ada beda tingkatan nyeri dismenorea primer antara sebelum dan sesudah mengkonsumsi placebo.

Apabila dilihat dari nilai mean dan t-hitung pada kedua kelompok, keduanya menunjukkan bahwa nilai mean dan thitung kelompok control (placebo) > kelompok perlakuan (ekstrak kunyit) yaitu mean 2,778>2,579 dan t-hitung 5,463>4,802, maka dapat disimpulkan bahwa pemberian ekstrak kunyit tidak efektif dalam mengurangi nyeri dismenorea primer.

\section{Analisis Perbedaan Efektivitas \\ Ekstrak Jahe dengan Ekstrak Kunyit dalam Mengurangi Nyeri Dismenorea Primer \\ Untuk mengetahui perbedaan} efektivitas ekstrak jahe dengan ekstrak kunyit dalam mengurangi nyeri dismenorhea primer, maka dilakukan 
perhitungan menggunakan one-way anova. Hasil analisis disajikan dalam tabel di bawah ini.

\begin{tabular}{|c|c|c|c|c|c|}
\hline \multirow{2}{*}{\multicolumn{6}{|c|}{$\begin{array}{c}\text { Tabel 4 } \\
\text { Uji Hipotesis Perbedaan Efektivitas } \\
\text { Ekstrak Jahe dengan Ekstrak Kunyit } \\
\text { dalam Mengurangi Nyeri Dismenorhea } \\
\text { Primer }\end{array}$}} \\
\hline & Sum of Squares & df & Mean Square & & Sig. \\
\hline $\begin{array}{l}\text { tween } \\
\text { oups }\end{array}$ & 32.388 & 2 & 16.194 & 3.284 & \\
\hline $\begin{array}{l}\text { Within } \\
\text { Sroups }\end{array}$ & 269.541 & 53 & 5.086 & & \\
\hline Total & 301.929 & 55 & & & \\
\hline
\end{tabular}

Berdasarkan tabel tersebut, dapat dilihat bahwa F-hitung $>$ F-tabel $=$ $3,28>3,17$, dan nilai $\mathrm{p}=0,04<0,05$, sehingga hipotesis diterima. Dapat disimpulkan bahwa terdapat perbedaan efektivitas ekstrak jahe dengan ekstrak kunyit dalam mengurangi nyeri dismenorhea primer, dimana ekstrak jahe lebih efektif dalam mengurangi nyeri dismenorea primer dibanding ekstrak kunyit.

\section{PEMBAHASAN}

Hasil penelitian yang didasarkan pada uji hipotesis, menunjukkan bahwa terdapat perbedaan efektivitas pengurangan nyeri dismenorea primer pada responden yang mengkonsumsi ekstrak jahe dengan ekstrak kunyit $(\mathrm{P}=0,04<0,05)$. Hasil uji hipotesis ini juga diperkuat dengan hasil uji beda antara masing-masing kelompok. Meskipun ekstrak jahe dan ekstrak kunyit samasama terbukti dapat mengurangi nyeri dismenorea primer (t-hitung $>\mathrm{t}$ tabel=2,101), namun disimpulkan bahwa ekstrak jahe lebih efektif dibanding ekstrak kunyit dalam mengurangi nyeri dismenore primer (t-hitung=9,690>4,802).
Efektifitas rimpang jahe dan kunyit dalam mengurangi nyeri dismenorea primer sudah terbukti secara ilmiah melalui suatu riset, baik dalam bentuk sediaan simplisia maupun ekstraksi. Salah satu penelitian tentang efektifitas penggunaan rimpang jahe dalam mengurangi nyeri dismenore primer pada remaja adalah penelitian yang dilakukan oleh Rahmana, et.al (2014) dengan judul "Effect of Zingiber officinale R. rhizomes (Ginger) on Pain Relief in Primary Dysmenorrhea", menyatakan bahwa pemberian terapi ekstrak jahe terbukti efektif mengurangi nyeri dismenore primer pada remaja dengan hasil $P$ kelompok perlakuan yang diberikan ekstrak jahe $(n=56)=0,015$, dan $P$ kelompok placebo $\quad(n=46)=0,029$. Penelitian lain tentang efek klinis jahe dalam mengobati dismenore primer dilakukan oleh Kashefi, et.al (2014) yang berjudul "Comparison of the Effect of Ginger and Zinc Sulfate on Primary Dysmenorrhea", didapatkan hasil bahwa jahe (ekstrak) dan zinc sulfat memiliki efek positif yang sama dalam pengurangan nyeri dismenore primer pada wanita muda, dari total responden 150 yang dibagi menjadi tiga kelompok (jahe, zinc sulfat dan placebo), dengan nilai $\mathrm{p}=0,001<0,05$.

Pemberian kunyit dalam mengurangi nyeri dysmenorrhea sudah dikenal luas oleh masyarakat pada umumnya. Penelitian tentang penggunaan simplisia kunyit guna mengurangi nyeri haid pernah dilakukan oleh Anindita (2010), dengan judul "Pengaruh Kebiasaan Mengkonsumsi Minuman Kunyit Asam terhadap Keluhan Dismenorea Primer pada Remaja Putri di Kotamadya Surakarta", didapatkan hasil $\mathrm{X} 2$ hitung $=25,4524>\mathrm{X} 2$ tabel $(\alpha=0,05)$ 
$=3,841$. Dapat disimpulkan bahwa terdapat pengaruh kebiasaan mengkonsumsi minuman kunyit asam terhadap keluhan dismenorea primer pada remaja putri di Kotamadya Surakarta. Penelitian serupa juga pernah dilakukan oleh Suciani, et.al (2012) tentang "Efektivitas Pemberian Rebusan Kunyit Asam terhadap Penurunan Dysmenorrea", menjelaskan bahwa pemberian rebusan kunyit asam efektif menurunkan nyeri dysmenorrhea, dengan hasil uji statistic $\mathrm{P}=0,01<0,05$.

Jahe, dengan nama ilmiah Zingiber officinale merupakan rimpang yang mengandung gingerol dan shogaols. Kandungan gingerol pada jahe dapat menghambat enzim cyclooxygenase dan lipooxygenase dalam sintesis prostaglandin dan leukotriene. Zat anti radang pada jahe juga dapat menghambat sintesis prostaglandin. Hal ini merupakan mekanisme kunci dari efek gingerol dalam mengurangi rasa nyeri saat menstruasi (Gizana, Lindmark, dkk, 2005). Jahe dapat merangsang pelepasan hormon adrenalin dan memperlebar pembuluh darah, akibatnya darah mengalir lebih cepat dan lancar dan memperingan kerja jantung memompa darah, sehingga dapat mengurangi rasa sakit.

Dapat dijelaskan lebih lanjut, bahwa inhibisi enzim siklooksigenase (COX-2) dapat mencegah kerusakan membran sel yang menghasilkan asam fosfolipase, asam fosfatase, dan ion kalsium guna terbentuknya asam arakidonat. Apabila pembentukan asam arakidonat dicegah, maka hasil metabolisme dari asam arakidonat berupa prostaglandin $\quad($ PGF2 $\alpha) \quad$ yang menyebabkan konstruksi artiole endometrium dan kontraksi miometrium yang menyebabkan terjadinya dismenore primer, dapat dicegah.

Penyebab terjadinya rasa nyeri dismenorrea adalah karena pengaruh terjadinya respons inflamasi akibat siklus prostaglandin dan leukotrienes. Kedua agen ini diproduksi oleh kerja metabolisme asam arachidonic. Prostaglandin distimulasi oleh enzim cyclooxygenase, sedangkan leukotriens oleh enzim lipooxygenase. Sintesis prostaglandin (PGF2-alfa) di dalam uterus akan berakibat pada hipertonus dan vasokonstriksi pada myometrium yang dapat menimbulkan iskemia dan nyeri pada dismenorea primer. Leukotrien lebih berperan dalam hal peningkatan sensitivitas serabut saraf yang menyebabkan sensasi nyeri pada uterus.

\section{KESIMPULAN DAN SARAN}

Terdapat perbedaan efektivitas ekstrak jahe dengan ekstrak kunyit dalam mengurangi nyeri dismenorea primer pada mahasiswi di asrama Kebidanan Politeknik Kesehatan Surakarta $(p=0,04<0,05)$. Ekstrak jahe lebih efektif dalam mengurangi nyeri haid dibanding ekstrak kunyit (t-hitung=9,690>4,802).

Berdasarkan hasil dan simpulan penelitian, maka peneliti memberikan saran-saran sebagai berikut:

\section{Bagi Tenaga Kesehatan}

Dysmenorrhea primer merupakan salah satu masalah pada kesehatan reproduksi yang harus ditangani dengan tepat. Disamping memberikan perawatan khusus, juga memberikan pengobatan yang efektif dan tepat waktu. Sebaiknya tenaga kesehatan tidak menganggap obat kimia sebagai pilihan pertama ketika berhadapan dengan dismenore primer, namun lebih memilih obat-obatan yang lebih aman berbahan dasar herbal, 
diantaranya adalah jahe dan kunyit. Konsumsi obat ini bisa dalam bentuk sediaan serbuk, kapsul, maupun simplisia. Pemilihan jahe lebih utama dibanding kunyit, disamping rasanya yang lebih segar, juga lebih efektif mengurangi dysmenorrhea.

\section{Bagi Responden}

Setiap perempuan hendaknya tidak menganggap dysmenorrhea primer sebagai keluhan yang ringan. Upaya penanganan yang tepat perlu diketahui dan diterapkan dengan bijak. Pemilihan obat berbahan dasar herbal lebih direkomendasikan. Perubahan gaya hidup yang lebih sehat secara signifikan dapat juga menurunkan tingkat nyeri, dengan menghindari menjadi perokok pasif, menghindari alcohol dan obat-obatan terlarang, berolahraga secara teratur, berfikir positif dan mengelola stres.

\section{Bagi Peneliti Selanjutnya}

Perlu dilakukan pengembangan penelitian sejenis dengan lebih memperhatikan variabel luar, terutama variable genetik, jenis diet setiap harinya, dan faktor psikis/stressor.

\section{DAFTAR RUJUKAN}

Anindita YA. (2010). Pengaruh Kebiasaan Mengkonsumsi Minuman Kunyit Asam Terhadap Keluhan Dismenorea Primer Pada Remaja Putri Di Kotamadya Surakarta, Skripsi. Fakultas Kedokteran, Universitas Sebelas Maret.

Desfietni V. (2012). Efektivitas kombinasi pemberian tekhnik nafas dalam dan terapi usik instrumental terhadap penurunan intensitas nyeri (dismenorea) pada remaja putri di SMPN 4 Kuantan Hilir, tidak dipublikasikan: Skripsi PSIK STIKKes hangtuah Pakanbaru.
Kashefi, Farzaneh; Khajehei, Marjan; Tabatabaeichehr, Mahbubeh; et. al. (2014). Comparison of the Effect of Ginger and Zinc Sulfate on Primary Dysmenorrhea. Pain Management Nursing, 2014;15(4):826-

833. http://www.medscape.com/vie warticle/835719_4

Leli, Rahmawati, Atik. (2011). Pengaruh kunyit asam terhadap penanganan nyeri haid pada siswi kelas XI SMA N $1 \quad$ Sugihwaras. http://journalakes.files.com/2012/06/ jurnal-akses-rejekwesi-vol-4.pdf. Diunduh pada 14 September 2014.

Lie, S. (2004). Terapi Vegetarian untuk Penyakit Kewanitaan. Jakarta: Prestasi Pustakaraya.

Rahnama et al. (2012). BMC Complementary and Alternative Medicine, 12:92. http://www.biomedcentral.com/1472 $-6882 / 12 / 92$.

Suciani, Sri; Utami, Sri; dan Dewi, Ari. (2012). Efektivitas Pemberian Rebusan Kunyit Asam Terhadap Penurunan Dismenorea. Publikasi penelitian: Program Studi Ilmu Keperawatan, Universitas Riau. http://jom.unri.ac.id/index.php/JOM PSIK/article/view/3527

Wilson LM, Price SA. (2006). Patofisiologi: konsep klinis prosesproses penyakit. Jakarta: Penerbit Buku Kedokteran EGC. 